\title{
Vigabatrin - new data on indications and safety in paediatric epilepsy
}

\author{
Weronika Golec ${ }^{1}$, Elżbieta Sołowiej ${ }^{1}$, Jolanta Strzelecka ${ }^{1}$, Elżbieta Jurkiewicz ${ }^{2}$, Sergiusz Jóźwiak ${ }^{1}$ \\ ${ }^{1}$ Department of Child Neurology, Medical University of Warsaw, Poland \\ ${ }^{2}$ Department of Diagnostic Imaging, The Children's Memorial Health Institute, Warsaw, Poland
}

\begin{abstract}
Introduction: Vigabatrin (VGB), a second-generation antiepileptic drug, is effective for the treatment of infantile spasms and focal seizures, primarily in tuberous sclerosis complex (TSC) patients. However, reports of adverse events of VGB, including VGB-associated visual field loss and brain abnormalities in neuroimaging, have raised concerns about the broader use of VGB and thus significantly limited its application.
\end{abstract}

Aim of the study: The goal of this review was to summarise the recent therapeutic guidelines, the use of VGB in focal seizures and new VGB applications as a disease-modifying treatment in TSC patients. Moreover, we discuss the current opinions on potential VGB-associated toxicity and the safety of VGB.

Key words: vigabatrin, infantile spasms, focal seizures, tuberous sclerosis complex, preventive treatment, VGB-associated visual field loss, VGB-associated brain abnormalities

(Neurol Neurochir Pol 2021; 55 (5): 429-439)

\section{Introduction}

Vigabatrin (VGB) (Sabril $\left.{ }^{\circ}\right)$ is a second-generation antiepileptic drug (AED) of which the therapeutic effect results from an increase in the level of gamma-aminobutyric acid (GABA), the main inhibitory neurotransmitter in the central nervous system (CNS), through the selective, irreversible inactivation of GABA transaminase (GABA-T) [1]. A study by Yang et al. suggests that VGB reduces glutamate/glutamine cycling between astrocytes and neurons. These findings imply a glutamatergic effect, which could also be related to VGB's anticonvulsant effect [2]. VGB is an antiseizure medication with proven efficacy in the treatment of infantile spasms (IS) and focal onset seizures, mainly in tuberous sclerosis complex (TSC) patients, but its use has been limited due to concerns about visual toxicity [3-5].

Despite its long history and some safety issues regarding the possibility of visual-field defects (VFDs), VGB retains a significant status in paediatric epileptology. This study reports recent recommendations and new indications for the use of VGB in focal seizures, trials of VGB application as a disease-modifying treatment in TSC, and current opinions on vigabatrin-dependent VFDs in epileptic patients.

\section{Registered indications and clinical guidelines}

VGB was first registered in the United Kingdom (UK) in 1989 for the treatment of IS and as a second-line treatment for uncontrolled focal seizures [1]. A growing number of reports of visual changes emerging for both paediatric and adult patients caused the European Medicines Agency (EMA) to update guidelines on VGB usage in 1999. The EMA limited VGB use to adjunctive therapy for refractory focal epilepsy in both adults and children and as monotherapy for IS [6]. Current therapeutic guidelines for VGB in Europe include: IS, an adjunctive therapy of refractory focal onset epilepsy, and in TSC patients as therapy in all types of seizures $[7,8]$.

Due to concerns over the safety of VGB treatment, the drug was not approved in the United States (US) until 2009. Nowadays, there are differences in the indications for VGB therapy guidelines in the US, including IS monotherapy in patients aged from 1 month to 2 years, and as adjunctive therapy in patients with refractory focal onset epilepsy $\geq 10$ years whose seizures have inadequately responded to several alternative treatments. For patients with TSC, indications include only IS monotherapy [9].

Address for correspondence: Sergiusz Jóźwiak, Department of Child Neurology, Medical University of Warsaw, Żwirki i Wigury 63A, 02-091 Warsaw, Poland; e-mail: sergiusz.jozwiak@gmail.com

Received: 17.05.2021 Accepted: 2.06.2021 Early publication date: 20.09.2021

This article is available in open access under Creative Common Attribution-Non-Commercial-No Derivatives 4.0 International (CC BY-NC-ND 4.0) license, allowing to download articles and share them with others as long as they credit the authors and the publisher, but without permission to change them in any way or use them commercially. 
VGB is particularly effective in epileptic seizures in patients in whom the epilepsy is caused by a genetic disorder, as in TSC cases [10]. In addition, recent data suggests that VGB may have not only antiseizure, but also antiepileptogenic or disease-modifying, properties in TSC [11]. This effect may be caused by the possible additional mechanism of action of VGB consisting in partial inhibition of the mTOR (mammalian target of rapamycin) pathway, which is dysregulated in the course of TSC [12].

\section{Therapeutic effectiveness of VGB}

VGB has proven to be highly effective in the treatment of IS especially in patients with TSC $[13,14]$. Data considering the effectiveness of VGB in focal seizures among paediatric patients is limited [15-17]. It seems certain that VGB therapy extends beyond IS in the paediatric population. Jackson et al. carried out a retrospective evaluation of the efficacy of VGB beyond the current U.S. Food and Drug Administration (FDA) approval recommendations [18]. Their study included 103 patients with different aetiologies and types of seizures (epileptic spasms, focal seizures, tonic seizures, tonic-clonic seizures), including a large percentage of treatment-resistant seizures under 11 years of age treated with VGB monotherapy and or adjuvant therapy. In this study, VGB has been shown to provide good seizure control: in short-term seizure outcome (median of 1.6 months), the seizure frequency decreased by 83.3\% from baseline, and $72.7 \%$ of patients achieved $\geq 50 \%$ seizure reduction. The improved seizure outcome was maintained also for long-term follow-up (median of 12.1 months), with $96.7 \%$ seizure frequency reduction and $72.7 \%$ of patients experiencing a reduction in seizure frequency of $\geq 50 \%$. In addition, a low relapse rate $(6.5 \%)$ following VGB therapy was demonstrated [18].

\section{VGB treatment efficacy in IS}

Infantile spasm is severe epileptic encephalopathy appearing with a frequency of 0.01 to $0.58 / 1,000$ live births which mainly affects children under the age of 2 years, peaking between 3 and 7 months $[19,20]$. Historically, the classic West syndrome triad has included the characteristic clinical seizures - epileptic spasms (ES) - sudden contraction of the trunk and extremities lasting less than one second, most frequently occurring in series, an abnormal interictal electroencephalographic (EEG) pattern (hypsarrhythmia), and developmental abnormalities. However, developmental delay and hypsarrhythmia do not always occur, especially at the beginning, which has led to the updating and broadening of the IS definition by the International League Against Epilepsy (ILAE) and the West Delphi Consensus Statement, according to which IS is recognised when characteristic ES are present, with or without the presence of hypsarrhythmia in $\operatorname{EEG}[21,22]$.
VGB is recommended as the first line treatment for IS, together with adrenocorticotropic hormone (ACTH) or corticosteroids. The effectiveness of the drug has been confirmed in several randomised controlled trials [13, 23]. Favourable long-term neurodevelopmental outcomes are associated with early ES cessation. It has been shown that the duration of hypsarrhythmia is a sensitive prognostic parameter in IS, and the risk of mental retardation increases after three weeks of hypsarrhythmia persistence in the EEG [24, 25].

Efficient diagnostics and quick treatment initiation have the greatest impact on the long-term outcomes of IS patients. In the United Kingdom Infantile Spasms Study (UKISS), O'Callaghan et al. presented the risk of delayed IS treatment [26]. Their study showed an inverse relationship between the length of treatment delay and the results of the Vineland Adaptive Behaviour Scales (VABS) in patients aged 4 years. A 3.9 point reduction in VABS score was associated with each successive delay interval as follows: $8-14$ days; $2-4$ weeks; 4-8 weeks; $>8$ weeks [26]. Widjaja et al. conducted a meta-analysis that included studies confirming the relationship between IS treatment delay and long-term outcomes. The authors proved that a lead time to treatment (LTTT) of $<4$ weeks was associated with a $51.9 \%$ improvement in neurodevelopmental outcome compared to a $>4$ weeks LTTT [25].

Several randomised, multicentre trials have been conducted to compare different IS therapeutic options. According to ILAE, short-term VGB response rates range from 35\% to $54 \%$, much less than with hormonal treatment (76-87\%) [22]. In the UKISS study, Lux et al. showed that infants assigned to hormonal therapy had a greater chance of not having ES on days 13 and 14 of treatment compared to those treated with VGB at the minimum dose of $100 \mathrm{mg} / \mathrm{kg} /$ day (73\% compared to $54 \%$ ) [27]. The same authors assessed patients aged 12-14 months, showing that long-term ES control in both treatment options was similar (hormonal vs VGB treatment, 75\% vs. 76\%) [28]. Moreover, the VABS neurological development score showed that in patients with an unknown IS aetiology, hormonal therapy promotes a better initial ES control which can lead to improved development [28].

The study by Djuric et al. also reported that long-term developmental outcomes in patients treated with VGB were similar to those in patients treated with ACTH or corticosteroids [29]. However, the continuation of the UKISS study with paediatric patients at mean age 4 years with a telephone epilepsy questionnaire and a VABS assessment showed that in cases of seizures without identified aetiology, patients treated with prednisolone or ACTH had better development than those treated with VGB [30]. The study by Knupp et al. proved that ACTH (all doses combined) was associated with a higher rate of early (at two weeks) response than VGB (55\% of infants receiving ACTH as initial treatment versus 36\% for VGB). The sustained response rate in patients treated with $\mathrm{ACTH}$, after relapse rates were taken into account, was still 
significantly higher compared to those treated with VGB at three months of therapy [31].

The International Collaborative Infantile Spasms Study (ICISS) was the first prospective work to evaluate the efficacy of combination therapy. This study determined that combination therapy (ACTH or high-dose steroids with VGB) was more effective and faster in achieving clinical and electroclinical responses in children with IS compared to treatment with hormonal therapy alone. Combination therapy has been proven to be much more effective in stopping ES (between 14 and 42 days of treatment inclusive) than hormonal therapy alone (71.9\% vs. $56.6 \%)$. Furthermore, this study also supports the fact that earlier ES termination correlates with better long-term epilepsy outcomes [32]. The patients from the ICISS were next evaluated after 18 months of treatment: combination therapy showed no improvement in developmental or treatment outcomes for epilepsy. [33]. Retrospective analysis by Hahn et al. also showed a similar result: patients receiving combination therapy with VGB and prednisolone showed a significantly better response to initial treatment than with VGB monotherapy (55.3\% vs. $39.1 \%)$ [34].

\section{VGB treatment efficacy in focal non-TSC seizures}

It is assumed that the administration of VGB in paediatric patients expands beyond IS. Although the available data is limited, several studies have demonstrated good efficacy of VGB in focal epilepsy in nonTSC patients $[16,17,35]$. A recent (2020) meta-analysis by Bresnahan et al. included 11 randomised, double-blind, placebo-controlled, fully published trials of VGB involving 756 people, which investigated VGB as an add-on treatment of drug-resistant focal epilepsy. This study included nonTSC patients aged 10 to 64 years. It has been shown that patients given VGB may be two to three times more likely to experience a $50 \%$ or greater reduction in seizure frequency compared to those treated with a placebo, and it is also suggested that patients given VGB may be up to three times more likely to stop treatment than people given a placebo. However, it has been evaluated that the results should not be related to children aged under 10 , and also that all studies had a significant risk of bias [36]. VGB treatment effectiveness in focal epilepsy in nonTSC and TSC paediatric patients is set out in Table 1.

\section{VGB in patients with TSC}

TSC is a genetic neurocutaneous disease caused by mutations of TSC1 or TSC2 suppressor genes, coding for the proteins hamartin and tuberin. Both of these proteins function as the mTOR inhibitory complex, which is involved in a number of cellular processes necessary for growth, metabolism and regulation of cell division. Mutations in any of the genes lead to upregulation of the mTOR pathway, resulting in uncontrolled cell growth and the formation of typical TSC changes $[37,38]$. Epilepsy is the most common neurological symptom of TSC, occurring in 70-90\% of patients, with a peak occurrence in the first year of life $[39,40]$. Patients with TSC can present almost any type of seizure, although focal seizures and ES are the most common. Moreover, subtle focal seizures may precede or coexist with ES [41, 42]. VGB is recognised as the most effective drug for all type of seizures in TSC patients. Moreover, it is more effective in treating IS than ACTH, eliminating ES in about 95\% of TSC patients [40]. VGB therapy is recommended in TSC both in IS and focal seizures because treatment can prevent the evolution of focal seizures into IS during the first year of life. According to the study by Overwater et al., focal seizures develop before infantile spasms in $58 \%$ of paediatric patients [40]. The recommendations of the International Tuberous Sclerosis Complex Consensus (2012 and 2018), in Europe, but not in the US, indicate VGB as a first-line drug for all seizures in paediatric patients with TSC under the age of 1 year. Furthermore, VGB therapy should also be considered for a variety of seizure types in older children and adults $[8,43]$. Accessible, mainly retrospective, studies have indicated the effectiveness of VGB treatment in TSC children with focal epilepsy [15-17, 35, 44]. A study conducted in 2015 showed that VGB is more effective when introduced as an initial treatment for TSC-related seizures [40]. A delay to VGB treatment is associated with unfavourable long-term outcomes, while early and aggressive treatment correlates with a lower percentage of refractory seizures [45]. Early seizure control plays a key role in reducing cognitive and behavioural function, and minimising the risk of autism and intellectual disability [46, 47]. Permanent remission of seizures seems to be a necessary condition for better development, including cognitive function, in patients with TSC [48]. In view of the above, Hussain et al. attempted to plan an effective strategy for the prevention of IS relapses. Their prospective study conducted on a group of patients with IS and TSC showed that each increase in the VGB dose by $50 \mathrm{mg} / \mathrm{kg} /$ day was associated with a $61 \%$ reduction in the risk of IS recurrence. In addition, the authors found that the risk of IS recurrence is exceptionally low with a VGB dose of at least $150 \mathrm{mg} / \mathrm{kg} /$ day. The results of this study suggest that treatment with high doses of VGB may reduce the risk of IS recurrence in TSC patients [49].

VGB is an example of a drug with individualised efficacy for seizures in TSC. The high efficacy of the drug in TSC is not yet clarified. In recent years, a vast amount of research has been conducted to explain the mechanism of the above correlation. Some of the investigators have indicated that the mTOR complex 1 (mTORC1) is involved in epileptogenesis in TSC and VGB can inhibit mTOR pathway [12, 50]. Deregulation of the mTOR pathway could have a potential antiepileptogenic effect or disease-modifying properties of VGB in TSC [11].

The recent reports on the possibility of preventing epilepsy in patients with TSC seem to be groundbreaking. Increased awareness of TSC symptoms, together with significant progress in early diagnosis, allows for implementation of regular 


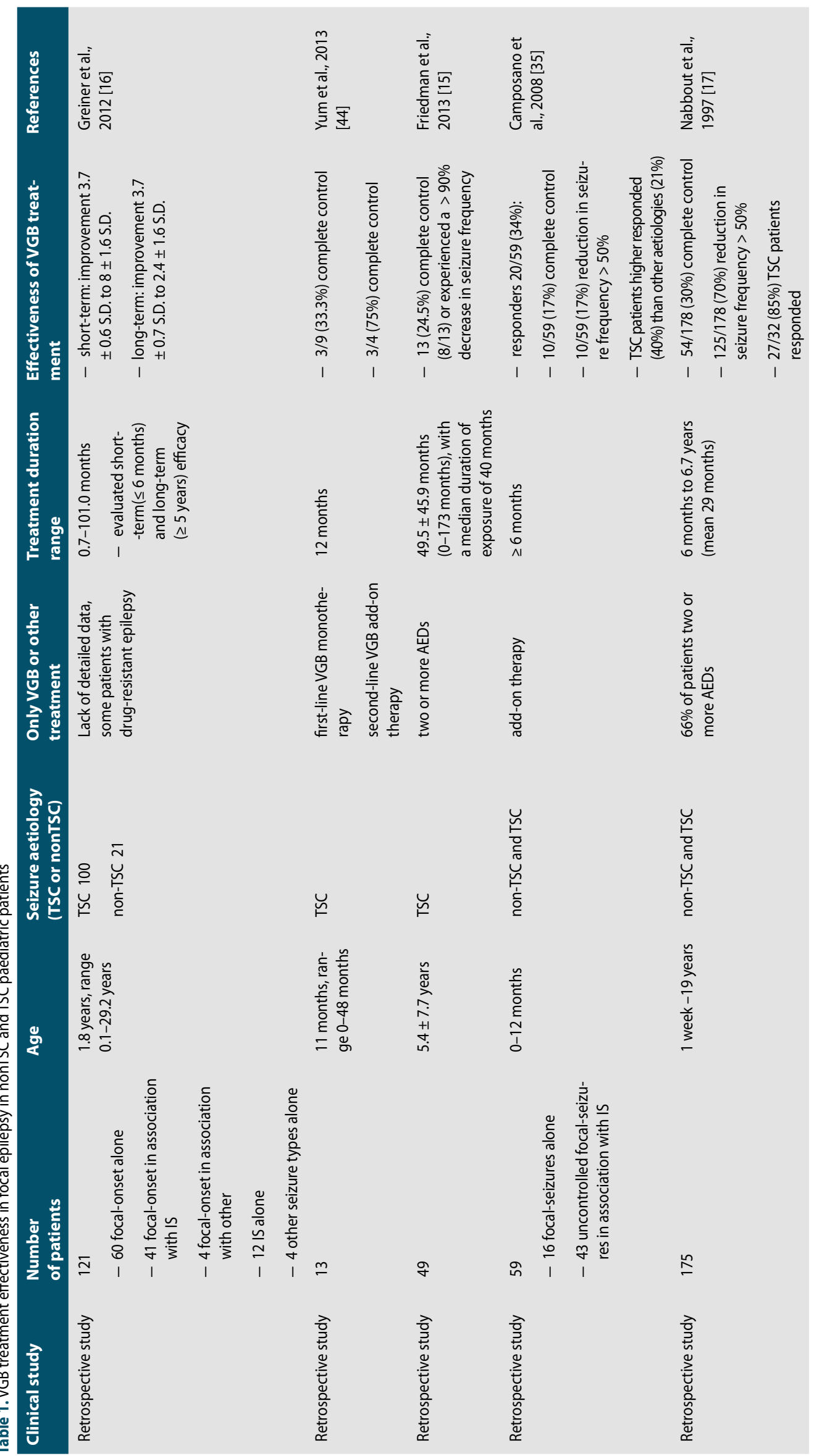


video-EEG surveillance and the introduction of VGB treatment before clinical seizures $[51,52]$. In the study by Jóźwiak et al., the initiation of VGB treatment (100-150 mg/kg/day) at the presence of subclinical epileptiform EEG before the onset of clinical seizures was associated at the $24^{\text {th }}$ month of life with a lower percentage of epilepsy ( $43 \%$ vs. $71 \%$ ), a lower incidence of drug-resistant epilepsy, and a lower rate of intellectual disability ( $48 \%$ vs. $14 \%$ ) compared to the group of patients treated conventionally after the onset of clinical seizures [45]. A longer follow-up of the same group demonstrated that the effects of preventive antiepileptic treatment introduced in infancy persisted until school age. Preventive treatment reduced the risk of clinical seizures ( $50 \%$ vs. $96 \%$ in the conventionally treated group) and intellectual disability (21\% vs. $72 \%$ ) in school-aged children with TSC [53].

Currently, two major prospective, randomised trials are evaluating the preventive use of VGB in TSC: the EPISTOP project (a long-term, prospective study evaluating clinical and molecular biomarkers of epileptogenesis in a genetic model of epilepsy - tuberous sclerosis complex, NCT02098759) and the PREVeNT trial (Preventing Epilepsy Using Vigabatrin in Infants With Tuberous Sclerosis Complex, NCT02849457) $[54,55]$. The PREVeNT study results are not yet available. The EPISTOP project focused not only on the prevention of epilepsy, but also on the identification of clinical and molecular biomarkers of epileptogenesis in patients with TSC. The project ended in 2018 and the clinical part of its results were published in 2021 [56]. They demonstrated that preventive treatment of VGB was associated with a more than two-fold reduction in the risk of drug-resistant epilepsy compared to conventional treatment ( $28 \%$ vs. $64 \%)$. The time to the first clinical seizure was longer (approximately $4 \mathrm{x}$ ) with preventive treatment. Moreover, the incidence of neurodevelopmental delay at age 2 years in the group with preventive treatment compared to conventional treatment was substantially lower (33\% vs. $50 \%)$. Most importantly, none of the EPISTOP patients had a severe learning disability (cognitive-developmental quotient $<50$ ) at age 2 years. None of the children who received preventive treatment developed IS throughout the course of the study, while $40 \%$ of patients on conventional treatment have. Furthermore, no adverse events related to preventive treatment were noted [56].

In conclusion, the results of the EPISTOP study showed that prophylactic antiepileptic treatment significantly reduces the risk of epilepsy, as well as its severity and the risk of drug resistance. Apart from the clinical part, for the first time, the EPISTOP project has undertaken comprehensive research with the use of currently available molecular methods aimed at detecting the mechanisms of epilepsy and its impact on the development of children. Work on this part of the project is still ongoing.

\section{Adverse events of VGB}

VGB is a well-tolerated drug; the most commonly reported adverse reactions are somnolence, sedation, irritability, and restlessness, but these are usually transient and dose-related $[57,58]$. Despite the recognised efficacy of the drug, the use of VGB has been limited by reports of rare, but significant and characteristic of VGB, side effects. The main one is retinopathy resulting in permanent defects of the peripheral visual field defects (pVFDs), termed Vigabatrin-associated visual field loss (VAVFL), and the other is toxicity presented in neuroimaging.

\section{Vigabatrin-associated visual field loss}

Retrospective studies describing visual field constrictions in both adult and paediatric patients are available, but the results are still inconclusive [59-62]. The meta-analysis by Maguire et al. demonstrated that the prevalence of VAVFL among patients treated for focal epilepsy was higher in adults (52\%) than in older children (34\%) [63]. In contrast, two other studies have reported visual fields loss in school-age children who had received VGB in infancy. The results of these studies showed a lower prevalence of pVFDs at school age, with mild pVFDs measured by Goldmann kinetic perimetry being observed in only $6-7 \%$ of children $[64,65]$. In a recently published cohort study, $21 \%$ of children treated with VGB for IS had a significant amplitude reduction in $30 \mathrm{~Hz}$ flicker electroretinogram (ERG) [66]. However, whether changes in ERG are a relevant marker of pVFD is debatable because ERG results change with development, and the reliability of the results in infants remains questionable.

In a study by Moskowitz et al., paediatric patients were assessed by both ERG and perimetry. This work demonstrated that there was no relationship between the amplitude of the $30 \mathrm{~Hz}$ flicker response and visual field defects on perimetry [67]. The onset of VAVFL is presumed to occur in the periphery (outside of the central 30-degree field of view), to progress centrally, and to persist after VGB has been discontinued $[68,69]$. The risk of vision loss is considered to be low with early exposure to VGB [70]. This risk may increase with age, higher cumulative doses of VGB, and with duration of treatment $[71,72]$. However, a systematic review by Maguire et al. demonstrated the association between VGB therapy and ocular toxicity to be minor and not sufficient to alter treatment decisions [63].

Due to the potentially serious side effect of permanent pVFDs, in accordance with the requirements of the FDA, VGB is available under a limited distribution programme known as the Risk Evaluation and Mitigation Strategy (REMS) which includes a mandatory registry and monitoring of patients treated with VGB (sabril.net/hcp/prescribing_sabril/) $[5,9]$. The REMS recommendations require an eye assessment at the start of treatment, every three months during treatment, and for 3-6 months after treatment. The recommended screening test is perimetry. For patients incapable of performing perimetry due to chronological age, developmental age, or cognitive difficulties, the recommended screening strategy consists of confrontational testing with ERG and optical coherence tomography (OCT) [73]. 
Based on the REMS registry of patients treated with VGB between 2009 and 2016, two studies were published describing demographics, disease characteristics and vision changes in 9,423 paediatric and adult patients $[74,75]$. These studies demonstrated that almost $30 \%$ of all patients enrolled in the VGB registry were exempt from ophthalmological testing. The drug registry received ophthalmological test results from only 1,509 patients, of whom $37 \%$ had preexisting, baseline clinically significant pathology affecting the visual system that was not related to VGB. The described data was next reviewed by two independent neuro-ophthalmologists who identified only 30 patients (2.0\%) with a potential VGB-associated effect on vision [76].

To further assess the influence of VGB on the visual system, Sergott et al. initiated in 2010 a prospective, longitudinal, single-arm, open-label phase IV study (NCT01278173) [77]. In this study, the effect of therapy was evaluated in VGB-naive patients during one year of adjunctive VGB treatment. The obtained results demonstrated that a substantial proportion of adult patients with refractory focal impaired awareness seizures had preexisting vision abnormalities prior to receiving VGB [32\% of patients had an abnormally thin retinal nerve fibre layer (RNFL), 15\% had abnormal visual acuity, and 20\% had abnormal near visual fields], and did not reveal statistically significant changes in population mean change from reference in central 30-degree visual field measurements. Moreover, in contrast to previous publications, the authors showed significant increases in RNFL thickness in spectral-domain optical coherence tomography (SD-OCT). The clinical relevance of retinal thickening is unclear, but the authors suggested that it may be caused by intra-axonal and intracellular oedema. Retrospective studies suggest that retinal toxicity occurs only after months to years of VGB therapy, therefore the short duration of follow-up (only one year) could be the limitation of this particular study [77].

There is more data concerning visual deficits in epileptic patients not exposed to VGB. In 2011, Plant and Sergott reported that bilateral constrictions of the visual field occur also in epilepsy patients who had not previously been treated with VGB [78]. In 2015, Balestrini et al. demonstrated that epilepsy patients treated with several AEDs (without VGB) and/or vagus nerve stimulator also exhibited abnormally thin RNFL compared to healthy controls, which could indicate that an abnormally thin RNFL may be associated with refractory epilepsy, sequelae, or possibly treatment-related with non-vigabatrin AEDs [79]. A study by Schwarz et al. did not detect any clinically apparent vision loss when evaluating 143 IS patients treated with VGB [80]. A recent study by McFarlane et al. demonstrated retinal toxicity with ERG in nearly a quarter of infants with IS who had not previously been treated with VGB. This study indicated an association of abnormal ERG (retinal damage) with the aetiology of IS which is a structurally-acquired (perinatal) subgroup, included a hypoxic-ischaemic defect. This was the first study on the incidence of retinal abnormalities in a large group of children with IS unrelated to VGB treatment. The authors found that nearly a quarter of children with IS not treated with VGB showed symptoms of a retinal defect identified in ERG responses. Nearly a quarter of the children in this study had structural perinatal brain damage [81].

The results of prospective observations which did not reveal new visual deficits led the FDA, in 2013, to lower the age (from 17 to 10) at which VGB can be prescribed to patients with refractory focal onset impaired awareness seizures. Moreover, in 2016, the wording in the package insert regarding eye examinations to monitor for drug toxicity was changed from "required" to "recommended". In addition, the "30 per cent or more" part of the ocular section of the black box warning has been omitted since 2016 compared to the previous prescribing information [76].

\section{VGB-associated brain abnormalities on magnetic resonance imaging (MRI)}

Another, poorly understood but definitely important, side effect is the risk of VGB-associated brain abnormalities on MRI (VABAM) in the form of predominantly asymptomatic and reversible high T2-weighted signal and restricted diffusion in the thalami, basal ganglia, brainstem tegmentum, and cerebellar dentate nuclei [82]. It is estimated that the risk of asymptomatic VABAM in infants is approximately $20-30 \%$, and so far no data in older children and adults is available $[82,83]$. The pathophysiological mechanism of VABAM is unclear. Initially MRI changes were thought to correlate with intramyelinic oedema [82]. However, there have been reports that MRI abnormalities are more likely due to axonal degeneration $[84,85]$. According to previous reports, VABAM correlates with high doses of VGB, younger age, and the 'cryptogenic' aetiology of IS [82, 86]. Moreover, isolated cases of VABAM are associated with hyperkinetic movement disorders as well as acute life-threatening encephalopathy and breathing difficulties, although the pathophysiology of these phenomena is unknown $[85,87,88]$. The study by Fong et al. undermined previously reported movement disorders related to VGB exposure, as there were identified cases where movement disorders occurred without MRI changes or VGB exposure, and in patients whose symptoms persisted despite VGB withdrawal, or resolved despite continuation of VGB [89]. Due to the high prevalence of asymptomatic VABAM in infants, and the rare but potentially life threatening effects of symptomatic VABAM, Hussain et al. designed a retrospective study in which the predictors of both symptomatic and asymptomatic VABAM were identified in IS patients [85]. The obtained results indicate that the risk of asymptomatic VABAM was dose-dependent and that peak (but not cumulative) VGB dose was strongly associated with asymptomatic VABAM. In addition, only four patients from a study group of 104 had symptomatic VABAM. It appears that the risk of symptomatic VABAM is dose-independent and potentially related to combining VGB with hormonal therapy [85]. 


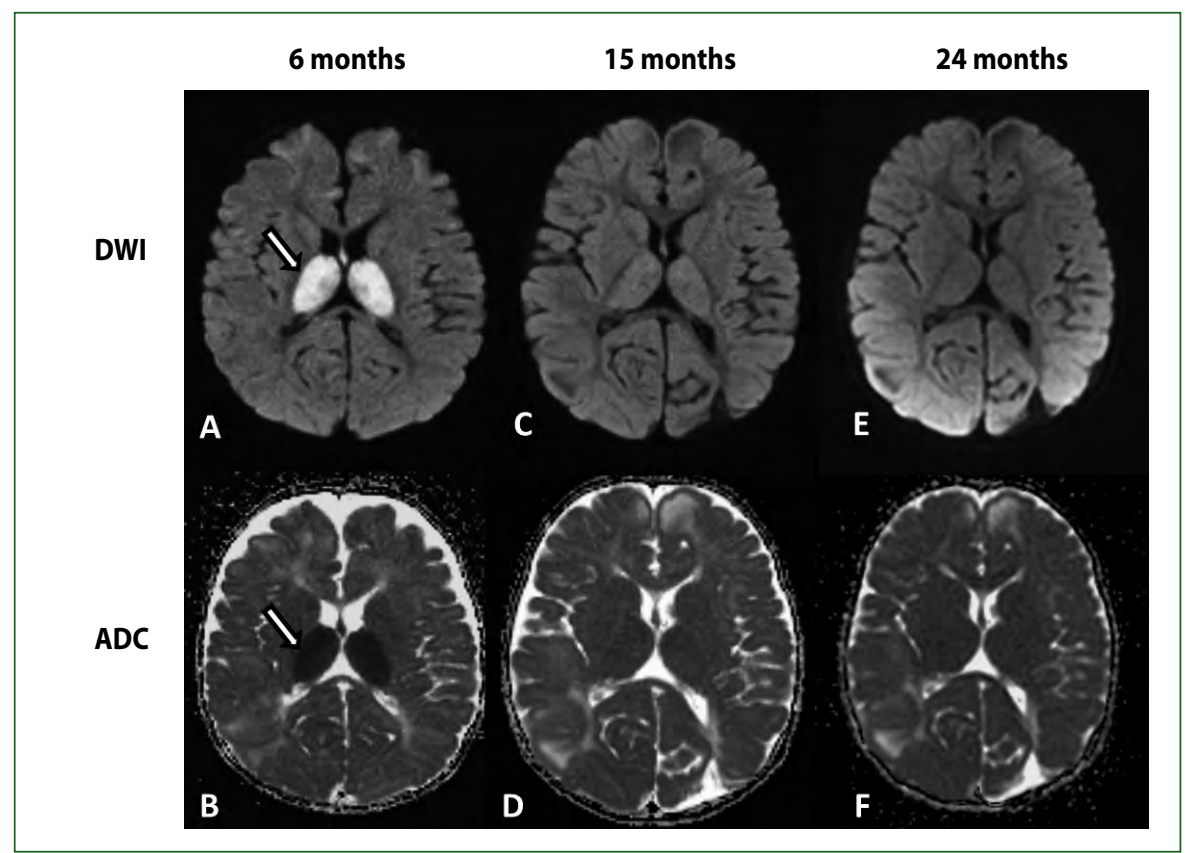

Figure 1. MRI abnormalities related to VGB. First column (A, B) shows MRI brain examination at age 6 months, second column (C, D) at age 15 months, and third column (E, F) at age 24 months. Treatment of VGB was continued. A. Diffusion-weighted images (DWI) with $b=1,000$ shows strong hyperintensity and symmetrical increased volume of both thalami; B. Corresponding apparent diffusion coefficient (ADC) map demonstrates hypointense signal consistent with restricted diffusion; C. Hyperintense signal of thalami slightly visible still on DWI, but signal on ADC map is normalised (D); E, F. Follow-up examination demonstrates resolution of diffusion abnormalities; images courtesy of Prof. Elżbieta Jurkiewicz, Department of Diagnostic Imaging, The Children's Memorial Health Institute, Warsaw, Poland

Individual reports of patients with concomitant encephalopathy and changes in neuroimaging during combination therapy have been reported in the literature [87]. A recent report describes an 8-month-old girl with IS treated with ACTH and high dose VGB $(182 \mathrm{mg} / \mathrm{kg} /$ day $)$, who developed encephalopathy and movement disorders with associated changes in imaging [90]. It seems that combination therapy, despite its better effectiveness, may carry a greater risk of VGB-related toxicity seen on MRI. The results of a study by the National Infantile Spasms Consortium which aims to compare combination therapy with hormonal therapy alone and VGB alone (ClinicalTrials.gov NCT03347526), may answer this question [91]. Figure 1 sets out reversible MRI abnormalities related to VGB.

It is important to distinguish between brain MRI results related to VGB from other aetiologies, including metabolic, infectious and ischaemic. In symptomatic VABAM, the symptoms should be confronted with the effects of epilepsy itself, which may lead to encephalopathy and developmental regression [85]. It is important to take into account the side effects of VGB, as misdiagnosis can lead to increased iatrogenic symptoms.

\section{Conclusions}

VGB is an antiepileptic drug used as first-line therapy in IS, a severe epileptic encephalopathy leading to developmental delay which frequently is a precursor of other forms of epilepsy (e.g. Lennox-Gastaut syndrome) $[5,13,22]$. In IS treatment, VGB's therapeutic effectiveness is weaker than other first line options such as ACTH and corticosteroids [22]. However, combined therapy of VGB and ACTH is significantly more effective and faster in achieving clinical and electroclinical responses in children with IS [32]. Nonetheless, in TSC epilepsy patients, VGB is highly effective both in IS treatment (eliminating $\mathrm{ES}$ in about $95 \%$ of patients) and for other seizure types including focal seizures that may occur prior to IS [40].

There have been groundbreaking recent reports on VGB's efficacy as a preventive epilepsy treatment. The results of several clinical studies and major prospective trials such as EPISTOP suggest that VGB may not only demonstrate antiseizure, but also antiepileptogenic, properties in TSC patients $[11,56]$. In fact, currently VGB is the only AED which has been proven effective in the prevention or modification of epilepsy.

It is clear that the use of VGB has been limited over the years due to reports of potential adverse effects. This was particularly noticeable in the US, where the drug was introduced with limited use in 2009, with the recommendation of regular monitoring of patients receiving VGB in the form of the REMS programme $[9,74,75]$. However, the suggestion of ocular toxicity originates from retrospective studies which did not include a pre-treatment ocular evaluation. Additionally, 
performing visual field examination in younger patients, especially those with neurological deficits, can be challenging and the peripheral nature of the field loss means there is no one ideal technique to assess VAVFL. Furthermore, prospective studies in the form of the VGB drug registry and the phase IV vision study by Sergott et al. did not demonstrate patients with symptomatic visual loss associated with VGB $[74,75,77]$. Considering the latest reports, it seems that the fear of severe adverse effects associated with VGB therapy, such as ocular toxicity, may be unfounded.

Despite multiple reports, VGB's therapeutic indications and possible antiepileptogenic properties are not ultimately established. Moreover, the risk and course of VGB's adverse effects are ambiguous. There are still many unanswered questions in the form of the frequency and severity of visual deficits caused by VGB. There is a need for more randomised, prospective and sufficiently extended trials which could definitively answer these important questions.

Acknowledgments: this work was supported by Medical Research Agency grant ViRAP No 2019/ABM/01/00034/P/06 and grant EPIMARKER of the Polish National Center for Research and Development No STRATEGMED3/306306/4/2016.

Conflict of interest: None.

\section{References}

1. Ben-Menachem E. Mechanism of action of vigabatrin: correcting misperceptions. Acta Neurol Scand Suppl. 2011(192): 5-15, doi: 10.1111/j.1600-0404.2011.01596.x, indexed in Pubmed: 22061176.

2. Yang J, Shen J. Elevated endogenous GABA concentration attenuates glutamate-glutamine cycling between neurons and astroglia. J Neural Transm (Vienna). 2009; 116(3): 291-300, doi: 10.1007/s00702009-0186-0, indexed in Pubmed: 19184333.

3. lannettiP,SpaliceA, Perla FM, etal. Visual field constriction in children with epilepsy on vigabatrin treatment. Pediatrics. 2000; 106(4): 838-842, doi: 10.1542/peds.106.4.838, indexed in Pubmed: 11015531.

4. Wohlrab G, Boltshauser E, Schmitt B, et al. Visual field constriction is not limited to children treated with vigabatrin. Neuropediatrics. 1999; 30(3): 130-132, doi: 10.1055/s-2007-973477, indexed in Pubmed: 10480207.

5. Elterman RD, Shields WD, Bittman RM, et al. Vigabatrin for the treatment of infantile spasms: final report of a randomized trial. J Child Neurol. 2010; 25(11): 1340-1347, doi: 10.1177/0883073810365103, indexed in Pubmed: 20404353.

6. European Medicines Agency. Opinion of the committee for proprietary medicinal products pursuant to article 12 of council directive 75/319/EEC as amended, for vigabatrin. 1999.

7. Specchio N, Pietrafusa N, Ferretti A, et al. Treatment of infantile spasms: why do we know so little? Expert Rev Neurother. 2020; 20(6): 551-566, doi: 10.1080/14737175.2020.1759423, indexed in Pubmed: 32316776.

8. van der Poest Clement E, Jansen FE, Braun KPJ, et al. Update on Drug Management of Refractory Epilepsy in Tuberous Sclerosis Complex. Paediatr Drugs. 2020; 22(1): 73-84, doi: 10.1007/s40272-01900376-0, indexed in Pubmed: 31912454.

9. Sabril [package insert]. Deerfield, IL: Lundbeck LLC; 2013. n.d.

10. Hancock E, Osborne JP. Vigabatrin in the treatment of infantile spasms in tuberous sclerosis: literature review. J Child Neurol. 1999; 14(2):
71-74, doi: 10.1177/088307389901400201, indexed in Pubmed: 10073425.

11. Klein $P$, Friedman $A$, Hameed MQ, et al. Repurposed molecules for antiepileptogenesis: Missing an opportunity to prevent epilepsy? Epilepsia. 2020; 61(3): 359-386, doi: 10.1111/epi.16450, indexed in Pubmed: 32196665.

12. Zhang Bo, McDaniel SS, Rensing NR, et al. Vigabatrin inhibits seizures and mTOR pathway activation in a mouse model of tuberous sclerosis complex. PLoS One. 2013; 8(2): e57445, doi: 10.1371/journal. pone.0057445, indexed in Pubmed: 23437388.

13. Wilmshurst JoM, Gaillard WD, Vinayan KP, et al. Summary of recommendations for the management of infantile seizures: Task Force Report for the ILAE Commission of Pediatrics. Epilepsia. 2015; 56(8): 1185-1197, doi: 10.1111/epi.13057, indexed in Pubmed: 26122601.

14. Thodeson D, Sogawa Y. Practice experience in the treatment of infantile spasms at a tertiary care center. Pediatr Neurol. 2014; 51(5): 696-700, doi: 10.1016/j.pediatrneurol.2014.07.019, indexed in Pubmed: 25175384.

15. Friedman D, Bogner M, Parker-Menzer K, et al. Vigabatrin for partial-onset seizure treatment in patients with tuberous sclerosis complex. Epilepsy Behav. 2013; 27(1): 118-120, doi: 10.1016/j.yebeh.2012.12.033, indexed in Pubmed: 23399947.

16. Greiner HM, Lynch ER, Fordyce S, et al. Vigabatrin for childhood partial-onset epilepsies. Pediatr Neurol. 2012; 46(2): 83-88, doi: 10.1016/j. pediatrneurol.2011.11.020, indexed in Pubmed: 22264701.

17. Nabbout RC, Chiron C, Mumford J, et al. Vigabatrin in partial seizures in children. J Child Neurol. 1997; 12(3): 172-177, doi: 10.1177/088307389701200304, indexed in Pubmed: 9130090.

18. Jackson MC, Jafarpour S, Klehm J, et al. Effect of vigabatrin on seizure control and safety profile in different subgroups of children with epilepsy. Epilepsia. 2017; 58(9): 1575-1585, doi: 10.1111/epi.13836, indexed in Pubmed: 28691157.

19. Jia JL, Chen S, Sivarajah V, et al. Latitudinal differences on the global epidemiology of infantile spasms: systematic review and meta-analysis. Orphanet J Rare Dis. 2018; 13(1): 216, doi: 10.1186/s13023 018-0952-x, indexed in Pubmed: 30486850.

20. Talwar D, Baldwin MA, Hutzler R, et al. Epileptic spasms in older children: persistence beyond infancy. Epilepsia. 1995; 36(2): 151-155, doi: 10.1111/j.1528-1157.1995.tb00974.x, indexed in Pubmed: 7821272.

21. Scheffer IE, Berkovic S, Capovilla G, et al. ILAE classification of the epilepsies: Position paper of the ILAE Commission for Classification and Terminology. Epilepsia. 2017; 58(4): 512-521, doi: 10.1111/ epi.13709, indexed in Pubmed: 28276062.

22. Messer R, Knupp KG. Infantile Spasms: Opportunities to Improve Care. Semin Neurol. 2020; 40(2): 236-245, doi: 10.1055/s-00401705121, indexed in Pubmed: 32143232.

23. Elterman RD, Shields WD, Bittman RM, et al. US Infantile Spasms Vigabatrin Study Group. Randomized trial of vigabatrin in patients with infantile spasms. Neurology. 2001; 57(8): 1416-1421, doi: 10.1212/ wnl.57.8.1416, indexed in Pubmed: 11673582.

24. Primec ZR, Stare J, Neubauer D. The risk of lower mental outcome in infantile spasms increases after three weeks of hypsarrhythmia duration. Epilepsia. 2006; 47(12): 2202-2205, doi: 10.1111/j.1528-1167.2006.00888.x, indexed in Pubmed: 17201726.

25. Widjaja E, Go C, McCoy B, et al. Neurodevelopmental outcome of infantile spasms: A systematic review and meta-analysis. Epilepsy Res. 2015; 109: 155-162, doi: 10.1016/j.eplepsyres.2014.11.012, indexed in Pubmed: 25524855. 
26. O'Callaghan FJK, Lux AL, Darke K, et al. The effect of lead time to treatment and of age of onset on developmental outcome at 4 years in infantile spasms: evidence from the United Kingdom Infantile Spasms Study. Epilepsia. 2011; 52(7): 1359-1364, doi: 10.1111/j.1528-1167.2011.03127.x, indexed in Pubmed: 21668442.

27. Darke K, Edwards SW, Hancock E, et al. trial steering committee on behalf of participating investigators, United Kingdom Infantile Spasms Study. The United Kingdom Infantile Spasms Study comparing vigabatrin with prednisolone or tetracosactide at 14 days: a multicentre, randomised controlled trial. Lancet. 2004; 364(9447): 1773-1778, doi: 10.1016/S0140-6736(04)17400-X, indexed in Pubmed: 15541450.

28. Lux AL, Edwards SW, Hancock E, et al. United Kingdom Infantile Spasms Study. The United Kingdom Infantile Spasms Study (UKISS) comparing hormone treatment with vigabatrin on developmental and epilepsy outcomes to age 14 months: a multicentre randomised trial. Lancet Neurol. 2005; 4(11): 712-717, doi: 10.1016/S1474-4422(05)70199-X, indexed in Pubmed: 16239177.

29. Djuric M, Kravljanac R, Tadic B, et al. Long-term outcome in children with infantile spasms treated with vigabatrin: a cohort of 180 patients. Epilepsia. 2014; 55(12): 1918-1925, doi: 10.1111/epi.12847, indexed in Pubmed: 25377998.

30. Darke K, Edwards SW, Hancock E, et al. trial steering committee on behalf of participating investigators. Developmental and epilepsy outcomes at age 4 years in the UKISS trial comparing hormonal treatments to vigabatrin for infantile spasms: a multi-centre randomised trial. Arch Dis Child. 2010; 95(5): 382-386, doi: 10.1136/ adc.2009.160606, indexed in Pubmed: 20457702.

31. Knupp KG, Coryell J, Nickels KC, et al. Pediatric Epilepsy Research Consortium. Response to treatment in a prospective national infantile spasms cohort. Ann Neurol. 2016; 79(3): 475-484, doi: 10.1002/ ana.24594, indexed in Pubmed: 26704170.

32. O'Callaghan FJK, Edwards SW, Alber FD, et al. participating investigators. Safety and effectiveness of hormonal treatment versus hormonal treatment with vigabatrin for infantile spasms (ICISS): a randomised, multicentre, open-label trial. Lancet Neurol. 2017; 16(1): 33-42, doi: 10.1016/S1474-4422(16)30294-0, indexed in Pubmed: 27838190.

33. O'Callaghan FJK, Edwards SW, Alber FD, et al. International Collaborative Infantile Spasms Study (ICISS) investigators. Vigabatrin with hormonal treatment versus hormonal treatment alone (ICISS) for infantile spasms: 18-month outcomes of an open-label, randomised controlled trial. Lancet Child Adolesc Health. 2018; 2(10): 715-725, doi: 10.1016/S2352-4642(18)30244-X, indexed in Pubmed: 30236380.

34. Hahn J, Park G, Kang HC, et al. Optimized treatment for infantile spasms: Vigabatrin versus Prednisolone versus combination therapy. J Clin Med. 2019; 8(10), doi: 10.3390/jcm8101591, indexed in Pubmed: 31581698.

35. Camposano SE, Major P, Halpern E, et al. Vigabatrin in the treatment of childhood epilepsy: a retrospective chart review of efficacy and safety profile. Epilepsia. 2008; 49(7): 1186-1191, doi: 10.1111/j.1528-1167.2008.01589.x, indexed in Pubmed: 18479386.

36. Bresnahan R, Gianatsi M, Maguire MJ, et al. Vigabatrin add-on therapy for drug-resistant focal epilepsy. Cochrane Database Syst Rev. 2020; 7: CD007302, doi: 10.1002/14651858.CD007302.pub3, indexed in Pubmed: 32730657.

37. Curatolo P, Bombardieri R, Jozwiak S. Tuberous sclerosis. The Lancet. 2008; 372(9639): 657-668, doi: 10.1016/s0140-6736(08)61279-9.

38. Stafstrom CE, Staedtke V, Comi AM. Epilepsy mechanisms in neurocutaneous disorders: tuberous sclerosis complex, neurofibromatosis type 1, and Sturge-Weber syndrome. Front Neurol. 2017; 8: 87, doi: 10.3389/fneur.2017.00087, indexed in Pubmed: 28367137.

39. Curatolo P, Nabbout R, Lagae L, et al. Management of epilepsy associated with tuberous sclerosis complex: Updated clinical recommendations. Eur J Paediatr Neurol. 2018; 22(5): 738-748, doi: 10.1016/j. ejpn.2018.05.006, indexed in Pubmed: 29880258.

40. Overwater IE, Bindels-de Heus K, Rietman AB, et al. Epilepsy in children with tuberous sclerosis complex: Chance of remission and response to antiepileptic drugs. Epilepsia. 2015; 56(8): 1239-1245, doi: 10.1111/epi.13050, indexed in Pubmed: 26046563.

41. Chu-Shore CJ, Major P, Camposano S, et al. The natural history of epilepsy in tuberous sclerosis complex. Epilepsia. 2010; 51(7): 1236-1241, doi: 10.1111/j.1528-1167.2009.02474.x, indexed in Pubmed: 20041940.

42. Kingswood JC, Belousova E, Benedik MP, et al. TOSCA Consortium and TOSCA Investigators. Epilepsy in tuberous sclerosis complex: Findings from the TOSCA study. Epilepsia Open. 2019; 4(1): 73-84, doi: 10.1002/epi4.12286, indexed in Pubmed: 30868117.

43. Krueger DA, Northrup H, Northrup H, et al. International Tuberous Sclerosis Complex Consensus Group, International Tuberous Sclerosis Complex Consensus Group. Tuberous sclerosis complex diagnostic criteria update: recommendations of the 2012 linternational Tuberous Sclerosis Complex Consensus Conference. Pediatr Neurol. 2013; 49(4): 243-254, doi: 10.1016/j.pediatrneurol.2013.08.001, indexed in Pubmed: 24053982.

44. Yum MS, Lee EH, Ko TS. Vigabatrin and mental retardation in tuberous sclerosis: infantile spasms versus focal seizures. J Child Neurol. 2013; 28(3): 308-313, doi: 10.1177/0883073812446485, indexed in Pubmed: 22752486.

45. Jóźwiak S, Kotulska K, Domańska-Pakieła D, et al. Antiepileptic treatment before the onset of seizures reduces epilepsy severity and risk of mental retardation in infants with tuberous sclerosis complex. Eur J Paediatr Neurol. 2011; 15(5): 424-431, doi: 10.1016/j. ejpn.2011.03.010, indexed in Pubmed: 21507691.

46. Bombardieri R, Pinci M, Moavero R, et al. Early control of seizures improves long-term outcome in children with tuberous sclerosis complex. Eur J Paediatr Neurol. 2010; 14(2): 146-149, doi: 10.1016/j. ejpn.2009.03.003, indexed in Pubmed: 19369101.

47. Cusmai R, Moavero R, Bombardieri R, et al. Long-term neurological outcome in children with early-onset epilepsy associated with tuberous sclerosis. Epilepsy Behav. 2011; 22(4): 735-739, doi: 10.1016/j.yebeh.2011.08.037, indexed in Pubmed: 22142783.

48. Riikonen RS. Favourable prognostic factors with infantile spasms. Eur J Paediatr Neurol. 2010; 14(1): 13-18, doi: 10.1016/j. ejpn.2009.03.004, indexed in Pubmed: 19362867.

49. Hussain SA, Schmid E, Peters JM, et al. Tuberous Sclerosis Complex Autism Center of Excellence Network. High vigabatrin dosage is associated with lower risk of infantile spasms relapse among children with tuberous sclerosis complex. Epilepsy Res. 2018; 148: 1-7, doi: 10.1016/j.eplepsyres.2018.09.016, indexed in Pubmed: 30296632.

50. Galanopoulou AS, Gorter JA, Cepeda C. Finding a better drug for epilepsy: the mTOR pathway as an antiepileptogenic target. Epilepsia. 2012; 53(7): 1119-1130, doi: 10.1111/j.1528-1167.2012.03506.x, indexed in Pubmed: 22578218.

51. Słowińska M, Jóźwiak S, Peron A, et al. Early diagnosis of tuberous sclerosis complex: a race against time. How to make the diagnosis before seizures? Orphanet J Rare Dis. 2018; 13(1): 25, doi: 10.1186/ s13023-018-0764-z, indexed in Pubmed: 29378663.

52. Słowińska M, Golec W, Jóźwiak S. Prevention of epilepsy in humans truth or myth? The experience from Sturge-Weber syndrome and Tube- 
rous Sclerosis Complex. Neurol Neurochir Pol. 2019; 53(3): 190-193, doi: 10.5603/PJNNS.a2019.0022, indexed in Pubmed: 31166003.

53. Jozwiak S, Słowińska M, Borkowska J, et al. Preventive antiepileptic treatment in tuberous sclerosis complex: A long-term, prospective trial. Pediatr Neurol. 2019; 101: 18-25, doi: 10.1016/j.pediatrneurol.2019.07.008, indexed in Pubmed: 31481332.

54. Preventing Epilepsy Using Vigabatrin In Infants With Tuberous Sclerosis Complex - Full Text View - ClinicalTrials.gov n.d. https://clinicaltrials.gov/ct2/show/NCT02849457 (February 21, 2021).

55. Long-term, Prospective Study Evaluating Clinical and Molecular Biomarkers of Epileptogenesis in a Genetic Model of Epilepsy - Tuberous Sclerosis Complex - Full Text View - ClinicalTrials.gov n.d. https://clinicaltrials.gov/ct2/show/NCT02098759 (February 21, 2021).

56. Kotulska K, Kwiatkowski DJ, Curatolo P, et al. EPISTOP Investigators. Prevention of epilepsy in infants with tuberous sclerosis complex in the EPISTOP trial. Ann Neurol. 2021; 89(2): 304-314, doi: 10.1002/ ana.25956, indexed in Pubmed: 33180985.

57. Carmant L. Vigabatrin therapy for infantile spasms: review of major trials in Europe, Canada, and the United States; and recommendations for dosing. Acta Neurol Scand Suppl. 2011(192): 36-47, doi: 10.1111/j.1600-0404.2011.01599.x, indexed in Pubmed: 22061179.

58. Moavero R, Pisani LR, Pisani F, et al. Safety and tolerability profile of new antiepileptic drug treatment in children with epilepsy. Expert Opin Drug Saf. 2018; 17(10): 1015-1028, doi: 10.1080/14740338.2018.1518427, indexed in Pubmed: 30169997.

59. Eke T, Talbot JF, Lawden MC. Severe persistent visual field constriction associated with vigabatrin. BMJ. 1997; 314(7075): 180-181, doi: 10.1136/bmj.314.7075.180, indexed in Pubmed: 9022432.

60. Krauss GL, Johnson MA, Miller NR. Vigabatrin-associated retinal cone system dysfunction: electroretinogram and ophthalmologic findings. Neurology. 1998; 50(3): 614-618, doi: 10.1212/wnl.50.3.614, indexed in Pubmed: 9521245.

61. Vanhatalo S, Pääkkönen L, Nousiainen I. Visual field constriction in children treated with vigabatrin. Neurology. 1999; 52(8): 1713-1714, doi: 10.1212/wnl.52.8.1713, indexed in Pubmed: 10331710.

62. Vanhatalo S, Nousiainen I, Eriksson K, et al. Visual field constriction in 91 Finnish children treated with vigabatrin. Epilepsia. 2002; 43(7): 748-756, doi: 10.1046/j.1528-1157.2002.17801.x, indexed in Pubmed: 12102679.

63. Maguire MJ, Hemming K, Wild JM, et al. Prevalence of visual field loss following exposure to vigabatrin therapy: a systematic review. Epilepsia. 2010; 51(12): 2423-2431, doi: 10.1111/j.1528-1167.2010.02772.x, indexed in Pubmed: 21070215.

64. Gaily E, Jonsson H, Lappi M. Visual fields at school-age in children treated with vigabatrin in infancy. Epilepsia. 2009; 50(2): 206-216, doi: 10.1111/j.1528-1167.2008.01961.x, indexed in Pubmed: 19215279.

65. Wohlrab G, Leiba H, Kästle R, et al. Vigabatrin therapy in infantile spasms: solving one problem and inducing another? Epilepsia. 2009; 50(8): 2006-2008, doi: 10.1111/j.1528-1167.2009.02167.x, indexed in Pubmed: 19682036.

66. Westall CA, Wright T, Cortese F, et al. Vigabatrin retinal toxicity in children with infantile spasms: An observational cohort study. Neurology. 2014; 83(24): 2262-2268, doi: 10.1212/WNL.00000000000001069, indexed in Pubmed: 25381295.

67. Moskowitz A, Hansen RM, Eklund SE, et al. Electroretinographic (ERG) responses in pediatric patients using vigabatrin. Doc Ophthalmol.
2012; 124(3): 197-209, doi: 10.1007/s10633-012-9320-7, indexed in Pubmed: 22426576.

68. Moseng L, Sæter M, Mørch-Johnsen GH, et al. Retinal nerve fibre layer attenuation: clinical indicator for vigabatrin toxicity. Acta Ophthalmol. 2011; 89(5): 452-458, doi: 10.1111/j.1755-3768.2010.02077.x, indexed in Pubmed: 21251242.

69. Nousiainen I, Mäntyjärvi M, Kälviäinen R. No reversion in vigabatrin-associated visual field defects. Neurology. 2001; 57(10): 1916-1917, doi: 10.1212/wnl.57.10.1916, indexed in Pubmed: 11723291.

70. Chiron C, Dulac 0. Epilepsy: Vigabatrin treatment and visual field loss. Nat Rev Neurol. 2011; 7(4): 189-190, doi: 10.1038/nrneurol.2011.25, indexed in Pubmed: 21364521.

71. Hardus P, Verduin WM, Engelsman M, et al. Visual field loss associated with vigabatrin: quantification and relation to dosage. Epilepsia. 2001; 42(2): 262-267, doi: 10.1046/j.1528-1157.2001.15000.x, indexed in Pubmed: 11240600.

72. Wild JM, Chiron C, Ahn H, et al. Visual field loss in patients with refractory partial epilepsy treated with vigabatrin: final results from an open-label, observational, multicentre study. CNS Drugs. 2009; 23(11): 965-982, doi: 10.2165/11317650-000000000-00000, indexed in Pubmed: 19845417.

73. Sergott R, Wheless J, Smith M, et al. Evidence-based review of recommendations for visual function testing in patients treated with vigabatrin. Neuro-Ophthalmology. 2010; 34(1): 20-35, doi: 10.3109/01658100903582498.

74. Pellock JM, Faught E, Foroozan $R$, et al. Which children receive vigabatrin? Characteristics of pediatric patients enrolled in the mandatory FDA registry. Epilepsy Behav. 2016; 60: 174-180, doi: 10.1016/j. yebeh.2016.03.030, indexed in Pubmed: 27208827.

75. Krauss G, Faught E, Foroozan R, et al. Sabril $囚$ registry 5-year results: Characteristics of adult patients treated with vigabatrin. Epilepsy Behav. 2016; 56: 15-19, doi: 10.1016/j.yebeh.2015.12.004, indexed in Pubmed: 26807550.

76. Foroozan R. Vigabatrin: lessons learned from the United States experience. J Neuroophthalmol. 2018; 38(4): 442-450, doi: 10.1097/ WN0.0000000000000609, indexed in Pubmed: 29280765.

77. Sergott RC, Johnson CA, Laxer KD, et al. Retinal structure and function in vigabatrin-treated adult patients with refractory complex partial seizures. Epilepsia. 2016; 57(10): 1634-1642, doi: 10.1111/epi.13495, indexed in Pubmed: 27580566.

78. Plant GT, Sergott RC. Understanding and interpreting vision safety issues with vigabatrin therapy. Acta Neurol Scand Suppl. 2011(192): 57-71, doi: 10.1111/j.1600-0404.2011.01601.x, indexed in Pubmed: 22061181.

79. Balestrini S, Clayton LMS, Bartmann AP, et al. Retinal nerve fibre layer thinning is associated with drug resistance in epilepsy. J Neurol Neurosurg Psychiatry. 2016; 87(4): 396-401, doi: 10.1136/jnnp-2015310521, indexed in Pubmed: 25886782.

80. Schwarz MD, Li M, Tsao J, et al. A lack of clinically apparent vision loss among patients treated with vigabatrin with infantile spasms: The UCLA experience. Epilepsy Behav. 2016; 57(Pt A): 29-33, doi: 10.1016/j.yebeh.2016.01.012, indexed in Pubmed: 26921595.

81. McFarlane MT, Wright T, McCoy B, et al. Retinal defect in children with infantile spasms of varying etiologies: An observational study. Neurology. 2020; 94(6): e575-e582, doi: 10.1212/ WNL.0000000000008686, indexed in Pubmed: 31792095.

82. Dracopoulos A, Widjaja E, Raybaud C, et al. Vigabatrin-associated reversible MRI signal changes in patients with infantile spasms. 
Epilepsia. 2010; 51(7): 1297-1304, doi: 10.1111/j.1528-1167.2010.02564.x, indexed in Pubmed: 20384718.

83. Wheless JW, Carmant L, Bebin M, et al. Magnetic resonance imaging abnormalities associated with vigabatrin in patients with epilepsy. Epilepsia. 2009; 50(2): 195-205, doi: 10.1111/j.1528-1167.2008.01896.x, indexed in Pubmed: 19054414.

84. Simao GN, Zarei Mahmoodabadi S, Snead OC, et al. Abnormal axial diffusivity in the deep gray nuclei and dorsal brain stem in infantile spasm treated with vigabatrin. AJNR Am J Neuroradiol. 2011; 32(1): 199-203, doi: 10.3174/ajnr.A2224, indexed in Pubmed: 20801762.

85. Hussain SA, Tsao J, Li M, et al. Risk of vigabatrin-associated brain abnormalities on MRI in the treatment of infantile spasms is dose-dependent. Epilepsia. 2017; 58(4): 674-682, doi: 10.1111/epi.13712, indexed in Pubmed: 28230253.

86. Pearl PL, Vezina LG, Saneto RP, et al. Cerebral MRI abnormalities associated with vigabatrin therapy. Epilepsia. 2009; 50(2): 184194, doi: 10.1111/j.1528-1167.2008.01728.x, indexed in Pubmed: 18783433.
87. Dill P, Datta AN, Weber P, et al. Are vigabatrin induced $T 2$ hyperintensities in cranial MRI associated with acute encephalopathy and extrapyramidal symptoms? Eur J Paediatr Neurol. 2013; 17(3): 311-315, doi: 10.1016/j.ejpn.2012.10.009, indexed in Pubmed: 23199677.

88. Hernández Vega Y, Kaliakatsos M, U-King-Im JM, et al. Reversible vigabatrin-induced life-threatening encephalopathy. JAMA Neurol. 2014; 71(1): 108-109, doi: 10.1001/jamaneurol.2013.1858, indexed in Pubmed: 24247994.

89. Fong CYi, Osborne JP, Edwards SW, et al. An investigation into the relationship between vigabatrin, movement disorders, and brain magnetic resonance imaging abnormalities in children with infantile spasms. Dev Med Child Neurol. 2013; 55(9): 862-867, doi: 10.1111/ dmcn.12188, indexed in Pubmed: 23789722.

90. Lotan E, Bluvstein J, Zan E. Vigabatrin toxicity in a patient with infantile spasms treated with concomitant hormonal therapy. Isr Med Assoc J. 2020; 22(7): 461-462.

91. A Novel Approach to Infantile Spasms - Full Text View - ClinicalTrials.gov n.d. https://clinicaltrials.gov/ct2/show/NCT03347526 (February 21, 2021). 